\title{
Nonallergic respiratory morbidity improved along with a decline of traditional air pollution levels: a review
}

\author{
J. Heinrich*
}

Nonallergic respiratory morbidity improved along with a decline of traditional air pollution levels: a review. J. Heinrich. (C) ERS Journals Ltd 2003.

ABSTRACT: The tremendous decline of combustion-derived emissions of traditional air pollutants such as sulphur dioxide $\left(\mathrm{SO}_{2}\right)$ and total suspended particles (TSP) in Eastern Germany shortly after German reunification in 1990 provided the unique opportunity to study trends of prevalence of respiratory illness along with the improvement of air quality.

The present review focused on the results of two repeated surveys of nonallergic respiratory illness in children living in East Germany. The crude prevalence of respiratory illness such as lifetime bronchitis, otitis media, tonsillitis, frequent colds, and frequent cough decreased during the 1990s in East German children. For two surveys the effect estimates showed consistently statistically significant association of TSP with bronchitis. For $\mathrm{SO}_{2}$ statistically significant associations with frequent colds were also consistently found, whereas at least one survey reported higher statistically significant effect estimates for tonsillitis, otitis media, frequent cough and reduced forced vital capacity.

The present study concludes that the prevalence of nonallergic respiratory illness in East German children is associated with sulphur dioxide and total suspended particles and that the improvement of air quality has beneficial effects on respiratory health. Eur Respir J 2003; 21: Suppl. 40, 64s-69s.
Correspondence: J. Heinrich GSF-Institute of Epidemiology P.O. Box 1129 D-85758 Oberschleissheim

Germany

Fax: 498931873380

E-mail: Joachim.Heinrich@gsf.de

Keywords: Air pollution

children

geographical differences

lung function

respiratory diseases

Received and accepted: April 122002
The German unification in 1990 has been a scientific opportunity to assess the effects of air pollution with a series of studies published since 1993. Some comparisons have been made with a neighbouring country, the Czech Republic.

\section{Background: studies on air pollution effects in Germany during the 1990s}

In East Germany ambient air pollution has been characterised by high concentrations of sulphur dioxide $\left(\mathrm{SO}_{2}\right)$ and total suspended particulates (TSP). Short-term effects of air pollution on daily mortality were investigated in Erfurt retrospectively for 1980-1989; logarithmic exposure-effect curves were found for both $\mathrm{SO}_{2}$ and suspended particulates (SP) [1-3]. A Northern Bohemian coal basin study in the Czech Republic showed a 3.8\% increase in mortality in association with $100 \mu \mathrm{g} \cdot \mathrm{m}^{-3}$ TSP (lagged 2 days) for the time period 1982-1994 [4]. In Erfurt, from 1995-1998 short-term effect studies showed an increased mortality in association with the level of ambient air pollution, including ultrafine and fine particles [5]. The associations tended to be stronger in winter and at ages $<70$ yrs. The overall association for respiratory diseases was slightly stronger than for cardiovascular diseases. Following changes in the two major emission sources (coal burning for power production and heating, and motor vehicles), substantially decreased (19-91\%) concentrations were observed for all pollutants, which may have led to decreased particle scavenging and, along with traffic-related changes, may be partially responsible for the observed increases in ultrafine particles [6, 7].

Whether the improved air quality with respect to level of TSP, particles with a 50\% cut-off aerodynamic diameter of
$2.5 \mu \mathrm{m}$ (PM2.5) and $\mathrm{SO}_{2}$, and the temporally changed particle size distributions has an impact on short-term air population effects is a very attractive question, which needs further investigation.

Some panel studies $[8,9]$ showed associations of air pollution (ultrafine and fine particles) with decreased peak expiratory flow (PEF) and increased symptoms. Asthmatic children increased their $\beta$-agonist use with an increase of sulphates, but medication use did not prevent decreases in PEF and increases in the prevalence of cough attributable to particulate air pollution [10].

A recent published panel study of 53 adult asthmatics in Erfurt found increased use of corticosteroids with a cumulative exposure over 14 days of ultrafine and fine particles [11]. $\beta_{2}$-agonist use was associated with 5-day mean of ultrafine particle number concentration and fine particle mass. Also asthma symptoms were more frequently reported at days with higher fine particle concentrations [11].

Children residing in industrial towns of Hettstedt and Bitterfeld had increased lifetime prevalence for physiciandiagnosed allergies, eczema, bronchitis, wheeze, shortness of breath, and cough without cold compared to children from Zerbst (less polluted control area). Sensitisation to common aeroallergens and specific immunoglobulin (Ig)E levels was more common for children from Hettstedt than from Zerbst [12, 13]. The annual mean TSP decreased from 1991 to 1998. The crude prevalence of bronchitis in the three respective areas decreased by $15 \%, 12 \%$, and $11 \%$ between 1992 and 1995 [14]; prevalence of nonallergic respiratory symptoms also decreased for an extended follow-up until 1999, indicating the reversibility of adverse health effects [14, 15]. This adds further evidence to a causal association between combustion-related air pollutants and childhood respiratory symptoms. 
In the framework of the multicentre European Community Respiratory Health Survey (ECRHS) the two German centres Erfurt (former East Germany) and Hamburg (former West Germany) were involved [16]. In the random sample of adults in Erfurt and Hamburg, 20-44 yrs, respiratory symptoms and diagnoses, bronchial hyperresponsiveness, atopic sensitisation (skin test and IgE), along with a lower mean number of siblings, a higher degree of childhood and current exposure to environmental tobacco smoke, and a higher frequency of fitted carpets and reported mould inside the house were more frequent in Hamburg than in Erfurt (higher pollution levels) [16].

In contrast to expectations in the early 1990 s, the prevalence rates of asthma, hay fever and allergic sensitisation were found to be higher in the (less polluted) city of Hamburg compared with the (heavily polluted) city of Erfurt [16]. Comparative indoor measurements determine why the prevalence rates of asthma and allergies were increased in Hamburg.

Indeed, higher concentrations for mite and cat allergens were found in Hamburg compared to Erfurt [17]. These differences between Hamburg and Erfurt were accounted for mainly by different building characteristics (age of houses, building material, story, and size of the dwelling), as well as by differences in other individual living habits (keeping of pets, age of carpets or mattresses, and cleaning routines) [17]. Further, measured Dermatophagoides pteronyssinus antigen 1 (Der p 1) and D. farinae antigen 1 (Der f 1 ) concentrations differed between both cities and both mite allergen concentrations should be measured in house dust, since they are only weakly correlated and have different determinants [18]. No significant difference could be shown for the total and for single genera in concentration of spores of viable fungi [19].

Exposure to mite and cat allergens $>10 \mu \mathrm{g} \cdot \mathrm{g}^{-1}$ of mattress dust increased the risk of wheeze and breathlessness and cough at night in this study [20].

Nitrogen dioxide $\left(\mathrm{NO}_{2}\right)$ indoor concentrations in Hamburg were slightly higher than those in Erfurt [21]. The most important predictors of indoor $\mathrm{NO}_{2}$ concentrations were gas cooking followed by other characteristics, such as ventilation, outdoor $\mathrm{NO}_{2}$ level (motor vehicle traffic, especially in Hamburg), and environmental tobacco smoke. Conversely, indoor and outdoor median volatile organic compound (VOCs) concentrations in Erfurt were slightly, but significantly higher than those in Hamburg [22]. In general, the indoor VOCs air concentrations were significantly higher than the outdoor concentrations, except for benzene. In Erfurt and Hamburg beta (1-->3)-glucan concentrations in house dust were found to be correlated with endotoxins, mite and cat allergens, and cultivable mould spores [23]. Significantly increased concentrations were linked to: carpets in the living room, keeping a dog inside, use of the home by four or more persons, use of the living room for $>180 \mathrm{hr} \cdot \mathrm{week}^{-1}$, lower frequency of vacuum cleaning and dust cleaning, and presence of mould spots during the past 12 months. Endotoxin concentrations in living-room floor dust sampled in homes without pets and vermin were lower than those sampled in homes with pets or vermin [24]. Endotoxin concentrations were higher in old buildings and in the lower storey of the dwelling, and were associated with longer occupancy in the apartment, high utilisation of the apartment during the sampling period, infrequent vacuum cleaning of the carpets, and an indifferent attitude to ventilation and keeping cats and dogs [25]. Summarising the results of comparative indoor measurements in Erfurt and Hamburg, it was concluded that despite detected regional differences, these differences probably only contribute a little to the different prevalences in atopic outcomes.

Additionally to the mite and cat allergens as typically indoor allergens, grass pollen allergen were also measured in settled dust indoors. From randomly selected homes in Hamburg, Erfurt, Hettstedt, Zerbst and Bitterfeld during 1995-1998, the amount of grass pollen allergen in mass units $(\mu \mathrm{g}$ Phleum pratense antigen $5(\mathrm{Phl} \mathrm{p} \mathrm{5))} \mathrm{in} \mathrm{dust} \mathrm{settled}$ indoors was detected in $67 \%$ of the samples analysed $(n=4,760)$. Phl p 5 levels were significantly higher in the dust from floors than in mattresses. There were fluctuations of indoor Phl p 5 levels with a peak in June but also annual differences. There was a partially higher concentration of indoor allergenic activity several weeks after the grass-pollen peak. A positive association was found between Phl p 5 levels and total dust amounts throughout the year [26, 27].

In 1,884 term and normal-weight neonates, during the first 6 months of life, the risk of eczema was significantly decreased by elevated endotoxin exposure in dust from mothers' mattresses, whereas the risk was increased for respiratory infections and cough with respiratory infection, bronchitis, and wheezing (LISA (influences of life-life related factors on the immune system and the development of allergies in childhood) study; [28]).

Within the LISA cohort study there was an association between prenatal endotoxin exposure and $\operatorname{IgE}$ production [29]. Additional support for the important role which endotoxin exposure might play comes from a cross-sectional study, which found an association between exposure to higher levels of house-dust endotoxin with lower prevalence of allergic sensitisation in children [30]. However, other factors than indoor exposure might also be involved in the development of atopic disease [31, 32].

\section{Background: studies on air pollution effects outside Germany}

In comparison with the huge number of studies on shortterm effects of air pollution, there are only a few studies investigating long-term effects of air pollution on respiratory morbidity in children. Most credible results come from crosssectional studies including 24 communities from USA and Canada [33, 34]. These studies showed a positive association between bronchitis rates and lung function decrements (forced vital capacity (FVC), forced expiratory volume in one second) with fine particle strong acidity and particles with a $50 \%$ cut-off aerodynamic diameter of $10 \mu \mathrm{m}$ (PM10) (only lung function measures). These studies confirmed former results of chronic particle exposure and chronic cough, chest illness and bronchitis including fewer communities (Harvard six cities study $[35,36])$. However, chronic effects on lung function have not been shown by these former studies [35-37]. Two recently published cohort study results on children's lung function and respiratory symptoms living in Southern California showed inconsistent results [38-41]. Whereas the cohort study by MCCONNEL et al. [41] in 1999 reported statistically significant effects between exposure to PM10 and bronchitis, phlegm and chronic cough in asthmatic children, studies by PETERS and coworkers [38, 39] did not find any statistically significant association between PM10 and symptoms, but an association with lung growth was found in the study by GAUDERMAN et al. [40].

Cross-sectional studies in Switzerland, Germany and Poland have reported statistically significant associations between TSP, PM10 and nonallergic respiratory symptoms [12, 42, 43] as well as between black smoke and $\mathrm{SO}_{2}$ and slowed lung function growth [44]. Uncontrolled regional confounding might be a major source of the inconsistent results of different cross-sectional studies. Therefore, studies including more communities are less susceptible to unexplained differences 
between geographical areas. Furthermore, the high correlation between different ambient air pollutants and the small number of included communities make it very difficult to separate pollutant specific effects.

\section{Aim}

Since the German reunification in 1990, the levels of $\mathrm{SO}_{2}$ and TSP in Eastern Germany have declined tremendously [5, $6,45]$, especially during the years 1990 and 1991. The closure of most of the industrial plants and the replacement of surface coal by natural gas for domestic heating contributed most to the decrease in $\mathrm{SO}_{2}$ and TSP.

If ambient TSP and $\mathrm{SO}_{2}$ levels were associated with a higher prevalence of bronchitic symptoms, and slowed lung function growth in children, a decline in these air pollution concentrations should produce a corresponding improvement of respiratory health. The current study reviewed results of repeated cross-sectional studies of nonallergic respiratory illness in children living in East Germany in order to examine the relationship between improvement of air quality and trends of prevalence of bronchitis, respiratory infections and adverse lung function measurements.

\section{Methods}

For the present review, repeated cross-sectional studies on East German children were looked at. Only studies which used identical methods in all surveys and which started before the middle of the 1990s, when air pollution levels were still quite high were considered for this review. Three studies were identified using children of different ages, but who were growing up in areas of the states of Sachsen and SachsenAnhalt (former East Germany) which are in close proximity.

\section{Results}

Table 1 gives an overview of the characteristics of the three reviewed studies. Examinations of $>14,000$ school beginners in each single school year 1991-1995 in four regions of Sachsen and Sachsen-Anhalt found a temporal decrease of prevalence of infectious airway diseases (bronchitis, tonsillitis, frequent colds, frequent cough) along with the strong decline in an annual mean of $\mathrm{SO}_{2}$ (67 (rural)-240 $\mu \mathrm{g} \cdot \mathrm{m}^{-3}$ (urban) in 1989-1990 versus $54-76 \mu \mathrm{g} \cdot \mathrm{m}^{-3}$ in 1993-1994) and TSP $\left(70-102 \mu \mathrm{g} \cdot \mathrm{m}^{-3}\right.$ in $1989-1990$ versus $46-53 \mu \mathrm{g} \cdot \mathrm{m}^{-3}$ in $\left.1993-1994\right)$
Table 2. - Adjusted effect estimates for sulphur dioxide $\left(\mathrm{SO}_{2}\right)$ and total suspended particles (TSP) on nonallergic respiratory symptoms (as odds ratio (OR) per increments of $\mathrm{SO}_{2}$ and TSP) and lung function (as means ratios in \% per decrease of $\mathrm{SO}_{2}$ and TSP) in the Bitterfeld Study (East Germany)

Bitterfeld Study

$\mathrm{SO}_{2}$ per $100 \mu \mathrm{g} \cdot \mathrm{m}^{-3} \mathrm{TSP}$ per $50 \mu \mathrm{g} \cdot \mathrm{m}^{-3}$

\begin{tabular}{lcc}
\hline Respiratory illness & & \\
Bronchitis (ever) $^{\#, \oplus}$ & $2.72(1.74-4.23)$ & $3.02(1.72-5.29)$ \\
Tonsillitis $^{\#,}$ & n.e. & n.e. \\
Otitis media $^{\#,-}$ & $1.42(0.94-2.15)$ & $1.45(0.89-2.37)$ \\
Frequent colds $^{\#, \S,+}$ & $1.81(1.23-2.68)$ & $1.90(1.17-3.09)$ \\
Frequent cough $^{\#}$ & $1.10(0.73-1.64)$ & $1.23(0.82-1.84)$ \\
Lung function $^{++}$ & & \\
FVC means ratio in \% & $4.9(0.7-9.3)$ & $4.7(0.2-9.5)$ \\
FEV1 means ratio in \% & $3.0(-1.1-7.2)$ & $2.9(-1.4-7.3)$
\end{tabular}

Data are presented as adjusted OR (95\% confidence intervals). \#: adjusted for age, sex, parental education, parental atopy, use of unvented gas cookers, dampness of flat, environmental tobacco smoke, contact with cats; ${ }^{\uparrow}$ : lifetime; ${ }^{\S}$ : past 12 months; ${ }^{+}$: defined as $>2$ in the Bitterfeld Study; ${ }^{++}$: repeated lung function measurements were performed only in sixth graders. Adjustment for height, season, lung function equipment, parental education, parental atopy, environmental tobacco smoke, and sex. FVC: forced vital capacity; FEV1: forced expiratory volume in one second; n.e.: not estimated. Source $[15,47]$.

[43]. Repeated cross-sectional studies of a total of 4,520 fourth graders in 1991-1992 and 1995-1996 revealed a decrease in the prevalence of bronchitis (32.2 versus $28.4 \%$ ) and nocturnal cough (5.7 versus $5.1 \%$ ) along with a decrease of an annual mean (1991 versus 1995) of $\mathrm{SO}_{2}$ (240 versus $76 \mu \mathrm{g} \cdot \mathrm{m}^{-3}$ ) and TSP $\left(79\right.$ versus $\left.53 \mu \mathrm{g} \cdot \mathrm{m}^{-3}\right)$ in the East German city of Leipzig [46]. Three repeated cross-sectional studies of a total of 7,611 East German children aged 5-14 yrs in the years 1992-1993, 1995-1996, and 1998-1999 found a statistical significant age-adjusted decrease for bronchitis (54.2 versus $38.0 \%$ ), otitis media (30.7 versus $26.7 \%$ ), sinusitis (4.6 versus $2.3 \%$ ), frequent colds (36.7 versus $28.5 \%$ ) and morning cough (13.4 versus $12.2 \%$ ) in parallel to an improvement of annual means of $\mathrm{SO}_{2}\left(60\right.$ versus $\left.8 \mu \mathrm{g} \cdot \mathrm{m}^{-3}\right)$ and TSP (56 versus $29 \%$ ) [15].

The design of two of these three studies allowed the contribution of ambient air pollution to the temporal changes of prevalence of respiratory illness to be modelled [15, 43]. In table 2 the effect estimates are given for $\mathrm{SO}_{2}$ and TSP on

Table 1.-Characteristics of the reviewed studies

\begin{tabular}{|c|c|c|c|}
\hline & Sachsen-Anhalt Study & Bitterfeld Study & Leipzig-Leipzig Study \\
\hline Areas & $\begin{array}{l}\text { Magdeburg, Halle, Leipzig, } \\
\text { Altmark (low pollution level) }\end{array}$ & $\begin{array}{l}\text { Bitterfeld, Hettstedt, Zerbst (low } \\
\text { pollution level) }\end{array}$ & Leipzig \\
\hline Primary study goal & $\begin{array}{l}\text { Estimation of chronic effects } \\
\text { of air pollution } \\
\text { Trends of prevalence of atopy }\end{array}$ & $\begin{array}{l}\text { Estimation of chronic effects of } \\
\text { air pollution } \\
\text { Trends of prevalence of atopy }\end{array}$ & Trends of prevalence of atopy \\
\hline Years of examination & $1991,1992,1993,1994,1995$ & 1992-1993, 1995-1996, 1998-1999 & 1991-1992, 1995-1996 \\
\hline Age of children yrs & $6-7$ & $5-14$ & $9-11$ \\
\hline Subjects n (total) & 14000 & 7500 & 3800 \\
\hline Participation rate $\%$ & $64-96$ & $75-89$ & $82-88$ \\
\hline $\mathrm{SO}_{2}$ & $20-70$ & $58-92$ & 70 \\
\hline TSP & $35-50$ & $39-64$ & 30 \\
\hline Reference & [43] & {$[12-15,47]$} & [46] \\
\hline
\end{tabular}

$\mathrm{SO}_{2}$ : sulphur dioxide; TSP: total suspended particles. 


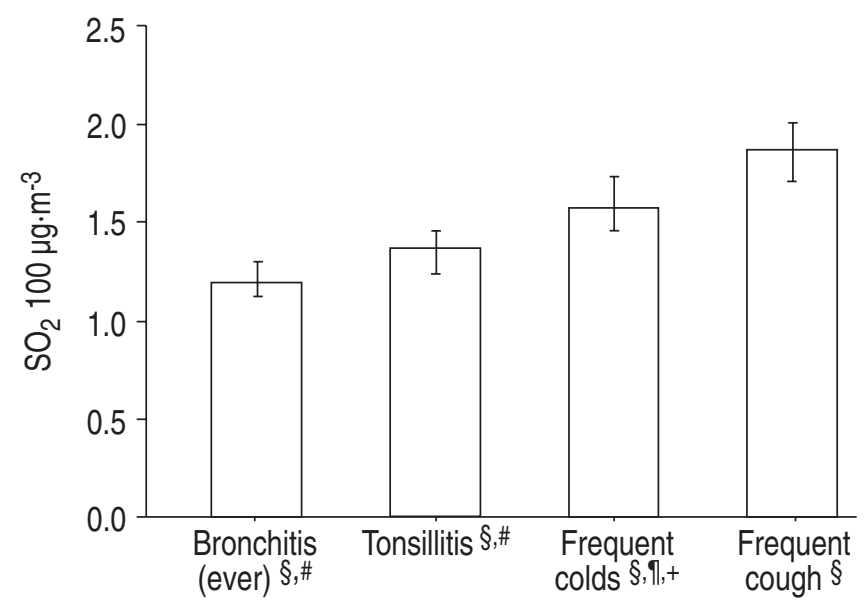

Fig. 1.-Adjusted effect estimates for sulphur dioxide $\left(\mathrm{SO}_{2}\right)$ on nonallergic respiratory illness (as odds ratio per $100 \mathrm{~g}$ increments of $\mathrm{SO}_{2}$ ), in the Sachsen-Anhalt Study (East Germany) [43]. \$: adjusted for age, sex, parental education, parental atopy, use of unvented gas cookers, dampness of flat, environmental tobacco smoke, contact with cats; ${ }^{\#}$ : lifetime; ${ }^{\uparrow}$ : past 12 months; ${ }^{+}$: defined as $>4$ in the SachsenAnhalt-Study. Source: U. Kraemer, Institut fuer Umweltforschung, Duesseldorf, Germany, personal Communication and [43].

respiratory illness and lung function. The effect estimates of the Sachsen-Anhalt Study [43] were recalculated in order to guarantee comparability to the Bitterfeld Study (U. Kraemer, Institut fuer Umweltforschung, Duesseldorf, Germany, personal communication). They showed consistently a statistically significant increased risk for bronchitis and frequent colds per increase of TSP and $\mathrm{SO}_{2}$. An increased risk per increase of $\mathrm{SO}_{2}$ was also found in at least one survey for tonsillitis, otitis media, frequent cough and reduced FVC (table 2, fig. 1 and 2). An adjustment for time trend (only reported for the Sachsen-Anhalt Study [43]) changed the effect estimates only marginally. Furthermore, the steepest temporal decline in TSP and $\mathrm{SO}_{2}$ was reported for those cities revealing the higher air pollution levels in the early 1990s [43]. One of these studies reported effect estimates stratified

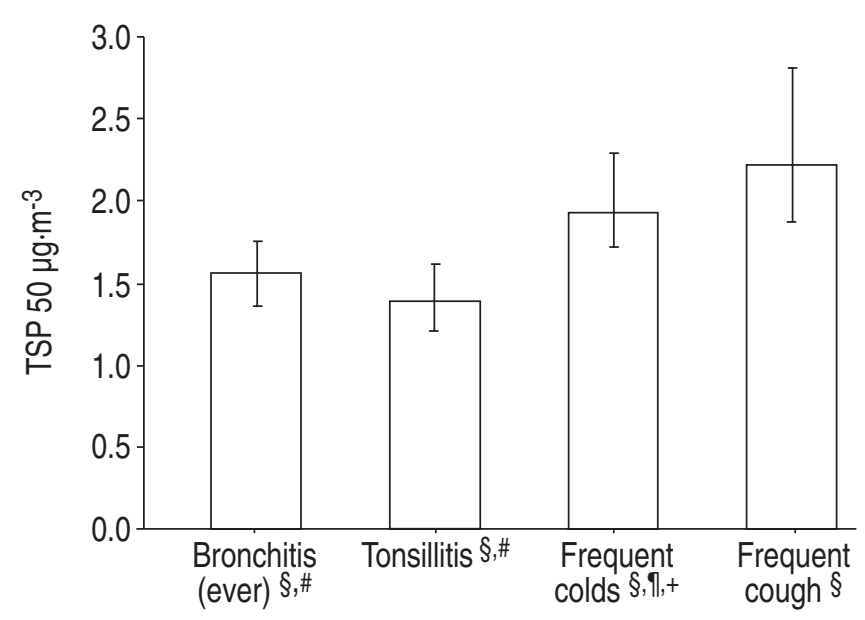

Fig. 2. - Adjusted effect estimates for total suspended particles (TSP) on nonallergic respiratory illness (as odds ratio per $50 \mu \mathrm{g}$ increment of TSP) in the Sachsen-Anhalt Study (East Germany) [43]. \$: adjusted for age, sex, parental education, parental atopy, use of unvented gas cookers, dampness of flat, environmental tobacco smoke, contact with cats; \#: lifetime; $\because$ : past 12 months; ${ }^{+}$: defined as $>4$ in the Sachsen-Anhalt-Study. Source: U. Kraemer, Institut fuer Umweltforschung, Duesseldorf, Germany, personal Communication and [43]. for children with and without indoor exposures such as those derived from parental tobacco smoke, emissions from gas stoves, mouldy or damp homes or from cats. Children without these indoor exposure revealed higher effect sizes and had a greater benefit from the improvement of air hygiene levels than children who were exposed to at least one of these indoor pollutants [15]. The effect size estimates for FVC were also higher in children not exposed to these indoor factors [47]. These effect estimates could not be separated for $\mathrm{SO}_{2}$ and TSP. The published effect estimates in the SachsenAnhalt Study were adjusted for each of the pollutants [43]. The $\mathrm{SO}_{2}$ effect for bronchitis and the TSP effect for tonsillitis and frequent cough were no longer statistically significant [43].

\section{Discussion}

The uniqueness of these reviewed studies results from the sudden drastic decline in air pollution concentration a few years after the year 1989. In contrast to many other crosssectional studies on long-term effects of ambient air pollution these studies have a rather unique design because in addition to the regional cross-sectional design they analysed temporal changes of respiratory morbidity along with improvements of air quality. The design lowered the risk of a bias caused by regional confounding, but increased a possible bias by temporal changes in morbidity rates.

Despite these differences, these findings are in close agreement with the results of studies in other geographic settings in the USA and Europe with different sources of air pollutants, using different air pollutant measurements and different epidemiological methods [48].

In these reviewed studies, statistically significant positive associations were found between particulate air pollution and nonallergic respiratory disorders such as bronchitis, frequent colds and chronic cough. These studies showed that increments of $10 \mu \mathrm{g} \cdot \mathrm{m}^{-3} \mathrm{PM} 10$ were associated with a $5-25$ per cent increase in bronchitis or chronic cough, whereas the highest increase of adverse health effects were reported for children [48]. The findings of the Bitterfeld Study correspond to a recalculated odds ratio of 1.24 for bronchitis for a $10-\mu \mathrm{g} \cdot \mathrm{m}^{-3}$ increment in TSP, which is similar to the recalculated odds ratio of 1.20 for a $10-\mu \mathrm{g} \cdot \mathrm{m}^{-3}$ increment in TSP (1.27 for a $10-\mu \mathrm{g} \cdot \mathrm{m}^{-3}$ increment in particles with a $50 \%$ cut-off aerodynamic diameter of $15 \mu \mathrm{m}$ (PM15)) in the Harvard Six Cities Study [36], and lower than the odds ratio of 1.40 for a $10-\mu \mathrm{g} \cdot \mathrm{m}^{-3}$ increment in PM10 in children from the SCARPOL (Swiss Study on Childhood Allergy and Respiratory Symptoms with Respect to Air Pollution) study [42].

The authors of the Sachsen-Anhalt Study and the Bitterfeld Study attempted to disentangle age-related effects from birth-cohort-related effects on the prevalence of nonallergic respiratory illness. The adjusted prevalence of bronchitis increased continuously in all age groups and even within the three birth cohort subgroups which were born before 1990 , the year of German re-unification [15]. All children investigated in the two other studies were born before the re-unification and were thus highly exposed during the 1980s. Nevertheless, even those children benefited from the improvements of air hygiene levels with increasing age. Presumably, the cumulative exposure a few years before the examination contributed more to health than an exposure in early infancy.

Each of these reviewed studies has several strengths and limitations. A major strength of all of these studies was that data showing strong improvement of air pollution levels within a rather short period could be used. Major limitations were the restriction of the analyses to TSP and $\mathrm{SO}_{2}$ due to a 
lack of data, the rather small number of included areas, and that one study was not originally designed to investigate health effects of ambient air pollutants.

The present study concludes that the prevalence of nonallergic respiratory illness in East German children is associated with $\mathrm{SO}_{2}$ and TSP and that the improvement of air quality has beneficial effects on respiratory health

Further studies are worthwhile in Europe to assess the temporal trends of the relationships of air pollution to respiratory health in another age-range of susceptible individuals, i.e. the elderly.

Acknowledgements. The recalculations of the effect estimates of the Sachsen-Anhalt Study by U. Kraemer is kindly acknowledged.

\section{References}

1. Spix C, Heinrich J, Dockery D, et al. Air pollution and daily mortality in Erfurt, East Germany, 1980-1989. Environ Health Perspect 1993; 101: 518-526.

2. Wichmann HE, Heinrich J. Health effects of high level exposure to traditional pollutants in East Germany - review and ongoing research. Environ Health Perspect 1995; 103: Suppl. 2, 29-35.

3. Brauer M, Dumyahn TS, Spengler JD, Gutschmidt K, Heinrich J, Wichmann HE. Measurement of acidic aerosol species in Eastern Europe: implications for air pollution epidemiology. Environ Health Perspect 1995; 103: 482-488.

4. Peters A, Skorkovsky J, Kotesovec F, et al. Associations between mortality and air pollution in central Europe. Environ Health Perspect 2000; 108: 283-287.

5. Wichmann HE, Spix C, Tuch T, et al. Daily mortality and fine and ultrafine particles in Erfurt, Germany part I: role of particle number and particle mass. Res Rep Health Eff Inst 2000; 98: 5-86.

6. Ebelt S, Brauer M, Cyrys J, et al. Air quality in postunification Erfurt, East Germany: associating changes in pollutant concentrations with changes in emissions. Environ Health Perspect 2001; 109: 325-333.

7. Pitz M, Kreyling WG, Hölscher B, Cyrys J, Wichmann HE, Heinrich J. Change of the ambient particle size distribution in East Germany between 1993 and 1999. Atmospheric Environment 2001; 35: 4357-4366.

8. Peters A, Goldstein IF, Beyer U, et al. Acute health effects of exposure to high levels of air pollution in Eastern Europe. Am J Epidemiol 1996; 144: 570-581.

9. Peters A, Wichmann HE, Tuch T, Heinrich J, Heyder J. Respiratory effects are associated with the number of ultrafine particles. Am J Respir Crit Care Med 1997; 155: 1376-1383.

10. Peters A, Dockery DW, Heinrich J, Wichmann HE. Medication use modifies the health effects of particulate sulfate air pollution in children with asthma. Environ Health Perspect 1997; 105: 430-435.

11. von Klot S, Wölke $\mathrm{G}$, Tuch $\mathrm{T}$, et al. Increased asthma medication use in association with ambient fine and ultrafine particles. Eur Respir J 2002; 20: 691-702.

12. Heinrich J, Hoelscher B, Wjst M, Ritz B, Cyrys J, Wichmann H. Respiratory diseases and allergies in two polluted areas in East Germany. Environ Health Perspect 1999; 107: 53-62.

13. Schafer T, Heinrich J, Wjst M, et al. Indoor risk factors for atopic eczema in school children from East Germany. Environ Res 1999; 81: 151-158.

14. Heinrich J, Hoelscher B, Wichmann HE. Decline of ambient air pollution and respiratory symptoms in children. $\mathrm{Am} \mathrm{J}$ Respir Crit Care Med 2000; 161: 1930-1936.

15. Heinrich J, Hoelscher B, Frye C, et al. Improved air quality in reunified Germany and decreases in respiratory symptoms. Epidemiology 2002; 13: 394401.

16. Nowak D, Heinrich J, Jorres R, et al. Prevalence of respiratory symptoms, bronchial hyperresponsiveness and atopy among adults: West and East Germany. Eur Respir $J$ 1996; 9: 2541-2552.

17. Fahlbusch B, Heinrich J, Gross I, Jager L, Richter K, Wichmann HE. Allergens in house-dust samples in Germany: results of an East-West German comparison. Allergy 1999; 54: 1215-1222.

18. Gross I, Heinrich J, Fahlbusch B, Jager L, Bischof W, Wichmann HE. Indoor determinants of Der $\mathrm{p} 1$ and Der $\mathrm{f} 1$ concentrations in house dust are different. Clin Exp Allergy 2000; 30: 376-382.

19. Koch A, Heilemann KJ, Bischof W, Heinrich J, Wichmann HE. Indoor viable mold spores - a comparison between two cities, Erfurt (Eastern Germany) and Hamburg (Western Germany). Allergy 2000; 55: 176-180.

20. Gehring U, Heinrich J, Jacob B, et al. Respiratory symptoms in relation to indoor exposure to mite and cat allergens and endotoxins. Indoor Factors and Genetics in Asthma (INGA) Study Group. Eur Respir J 2001; 18: 555-563.

21. Cyrys J, Heinrich J, Richter K, Wolke G, Wichmann HE. Sources and concentrations of indoor nitrogen dioxide in Hamburg (West Germany) and Erfurt (East Germany). Sci Total Environ 2000; 250: 51-62.

22. Schneider P, Gebefugi I, Richter K, et al. Indoor and outdoor BTX levels in German cities. Sci Total Environ 2001; 267: 41-51.

23. Gehring U, Douwes J, Doekes G, et al. Beta(1-->3)-glucan in house dust of German homes: housing characteristics, occupant behavior, and relations with endotoxins, allergens, and molds. Environ Health Perspect 2001; 109: 139-144.

24. Heinrich J, Gehring U, Douwes J, et al. Pets and vermin are associated with high endotoxin levels in house dust. Clin Exp Allergy 2001; 31: 1839-1845.

25. Bischof W, Koch A, Gehring U, Fahlbusch B, Wichmann HE, Heinrich J. Predictors of high endotoxin concentrations in the settled dust of German homes. Indoor Air 2002; 12: 2-9.

26. Fahlbusch B, Hornung D, Heinrich J, Dahse HM, Jager L. Quantification of group 5 grass pollen allergens in house dust. Clin Exp Allergy 2000; 30: 1645-1652.

27. Fahlbusch B, Hornung D, Heinrich J, Jager L. Predictors of group 5 grass-pollen allergens in settled house dust: comparison between pollination and non-pollination seasons. Allergy 2001; 56: 1081-1086.

28. Gehring U, Bolte G, Borte M, et al. Exposure to endotoxin decreases the risk of atopic eczema in infancy: a cohort study. J Allergy Clin Immunol 2001; 108: 847-854.

29. Heinrich J, Bolte G, Hölscher B, et al. Allergens and endotoxin on mothers' mattresses and total immunoglobulin E in cord blood of neonates. Eur Respir J 2002; 20: 617623.

30. Gehring U, Bischof W, Fahlbusch B, Wichmann HE, Heinrich $\mathbf{J}$ and for the INGA Study Group. House dust endotoxin and allergic sensitization in children. Am J Respir Crit Care Med 2002; 166: 939-944.

31. Gehring U, Cyrys J, Sedlmeir G, et al. Traffic-related air pollution and respiratory health during the first 2 yrs of life. Eur Respir J 2002; 19: 690-698.

32. Wjst M, Hölscher B, Frye C, Wichmann HE, Dold S, Heinrich J. Early antibiotic treatment and later asthma. Eur J Med Res 2001; 6: 263-271.

33. Dockery DW, Cunningham J, Damokosh AI, et al. 1996 Health effects of acid aerosols on North American children: respiratory symptoms. Environ Health Perspect 1996; 104: 500-505.

34. Raizenne M, Neas LM, Damokosh AI, et al. Health effects of acid aerosols on North American children: pulmonary function. Environ Health Perspect 1996; 104: 506-514.

35. Ware JH, Ferris BG Jr, Dockery DW, Spengler JD, Stram DO, Speizer FE. Effects of ambient sulfur oxides 
and suspended particles on respiratory health of preadolescent children. Am Rev Respir Dis 1986; 133: 834-842.

36. Dockery DW, Speizer FE, Stram DO, Ware JH, Spengler JD, Ferris BG Jr. Effects of inhalable particles on respiratory health of children. Am Rev Respir Dis 1989; 139: 587-594.

37. Neas LM, Dockery DW, Ware JH, Spengler JD, Ferris BG Jr, Speizer FE. Concentration of indoor particulate matter as a determinant of respiratory health in children. $A m J$ Epidemiol 1994; 139: 1088-1099.

38. Peters J, Avol E, Navidi W, et al. A study of twelve Southern California communities with differing levels and types of air pollution. I: Prevalence of respiratory morbidity. Am J Respir Crit Care Med 1999; 159: 760-767.

39. Peters JM, Avol E, Gauderman WJ, et al. A study of twelve Southern California communities with differing levels and types of air pollution. II. Effects on pulmonary function. Am J Respir Crit Care Med 1999; 159: 768-775.

40. Gauderman WJ, McConnel R, Gilliland F, et al. Association between air pollution and lung function growth in Southern California children. Am J Respir Crit Care Med 2000; 162: 1383-1390.

41. McConnell R, Berhane K, Gilliland F, et al. Air pollution and bronchitic symptoms in Southern California children with asthma. Environ Health Perspect 1999; 107: 757-760.

42. Braun-Fahrländer $\mathrm{J}$, Vuille $\mathrm{C}$, Sennhauser $\mathrm{FH}$, et al.
Respiratory health and long-term exposure to air pollutants in Swiss schoolchildren. Am J Respir Crit Care Med 1997; 155: 1042-1049.

43. Kraemer U, Behrendt H, Dolgner R, et al. Airway diseases and allergies in East and West German children during the first 5 years after reunification: time trends and the impact of sulphur dioxide and total suspended particles. Int J Epidemiol 1999; 28: 865-873

44. Jedrychowski W, Flak E. Effects of air quality on chronic respiratory symptoms adjusted for allergy among preadolescent children. Eur Respir J 1998; 11: 1312-1318.

45. Daten zur Umwelt (environmental data book) 1995/96. Berlin, Umweltbundesamt, Erich Schmidt Verlag, 1997.

46. von Mutius E, Weiland SK, Fritzsch C, Duhme H, Keil U. Increasing prevalence of hay fever and atopy among children in Leipzig, East Germany. Lancet 1998; 351: 862-866.

47. Frye C, Hoelscher B, Cyrys J, Wjst M, Wichmann HE, Heinrich J. Association of lung function with declining ambient air pollution. Environ Health Perspect 2003; 111: 383-388.

48. Pope CA, Dockery DW. Epidemiology of particle effects. In: Holgate ST, Samet JM, Koren HS, Maynard RL, eds. Air Pollution and Health. San Diego, London, Boston, New York, Sydney, Tokyo, Toronto, Academic Press, 1999. 